\title{
Erythrocyte Membrane Rigidity Induced by Glycophorin A-Ligand Interaction Evidence for a Ligand-induced Association between Glycophorin A and Skeletal Proteins
}

\author{
Joel Anne Chasis, Narla Mohandas, and Stephen B. Shohet \\ Departments of Medicine and Laboratory Medicine, Cancer Research Institute, \\ University of California, San Francisco, California 94143
}

\begin{abstract}
Erythrocyte skeletal proteins are known to play an important role in determining membrane deformability. In order to see whether transmembrane proteins also influence deformability and, if so, whether this influence is mediated by an interaction with the membrane skeleton, we examined the effect on deformability of ligands specific for transmembrane proteins. We found membrane deformability markedly reduced in erythrocytes that were pretreated with glycophorin A-specific ligands. In contrast, ligands specific for band 3 and $A$ and $B$ blood group antigens had no effect. The increase in membrane rigidity appeared to depend upon a transmembrane event and not upon a rigidity-inducing lattice on the outside surface of the cell in that a monovalent Fab of antiglycophorin IgG caused decreased deformability. We therefore looked for a ligand-induced association of glycophorin and the skeletal proteins and found, in Triton X-100-insoluble residues, a partitioning of glycophorin with the skeletal proteins only after preincubation with a ligand specific for glycophorin. We then studied cells and resealed membranes with skeletal protein abnormalities. In spectrin-deficient and protein 4.1-deficient erythrocytes and in 2,3-diphosphoglycerate-treated resealed membranes, the antiglycophorin IgG was only one-third as effective in decreasing deformability as it was in normal cells. Thus, normal skeletal proteins appear to be essential for liganded glycophorin to affect membrane deformability maximally. Taken together, these observations indicate that there is a ligand-induced interaction between glycophorin $A$ and skeletal proteins and that this interaction can directly influence membrane deformability.
\end{abstract}

\section{Introduction}

The erythrocyte transmembrane protein glycophorin $A$ is structurally characterized and known to possess the antigenic sites for the MN blood groups (1-4). However, the role of glycophorin $\mathrm{A}$ in the biology of the erythrocyte has not yet been elucidated. Membrane spanning proteins in other cell systems have been shown to interact with proteins on the cytoplasmic surface of the membrane and play a role in cellular events such as cell attachment to surfaces (5) and the capping phenomena (6). In the erythrocyte, the skeletal proteins spectrin,

This material was presented in part to the American Society of Hematology, San Francisco, CA, 1983.

Received for publication 6 February 1984 and in revised form 12 February 1985.

J. Clin. Invest.

(c) The American Society for Clinical Investigation, Inc.

0021-9738/85/06/1919/08 $\$ 1.00$

Volume 75, June 1985, 1919-1926 actin, protein 4.1 , and protein 2.1 are localized on the cytoplasmic surface of the membrane, forming a network underlying the lipid bilayer and associated with it through 2.1 binding to band 3 and spectrin binding to anionic phospholipids $(7,8)$. These skeletal proteins are known to play an important role in determining membrane deformability primarily through their influence on the membrane material properties such as the elastic shear modulus and the coefficient of surface viscosity (9-11). Because of their influence on deformability, these skeletal proteins are also involved in shape change in that, without a deformable membrane, cell shape cannot change (12).

Whether any of the erythrocyte transmembrane proteins influence cell deformability or shape has not yet been definitively shown. Lovrien and Anderson $(13,14)$ suggested that glycophorin A might play a role in modulating changes in cell shape; they showed that erythrocytes preincubated with wheat germ agglutinin (WGA) ${ }^{1}$ were protected from the diskocyte to echinocyte conversion triggered either by organic anions or elevated cytoplasmic calcium. Because WGA binds to sialic acid residues on glycophorin (15), they concluded that WGA altered membrane properties through glycophorin and hypothesized an interaction of glycophorin A with the erythrocyte skeletal proteins. In additional studies, Smith and Hochmuth (16) examined the effect of WGA on the viscoelastic properties of erythrocyte membranes by using micropipette techniques to measure the elastic shear modulus and the coefficient of surface viscosity. They found that WGA, in the presence of albumin, increased membrane viscosity. In that the coefficient of surface viscosity is known to be predominantly regulated by membrane skeletal proteins $(9-11)$, this finding further suggests an interaction between glycophorin $A$ and skeletal proteins in the presence of a ligand with specificity for glycophorin.

In light of these studies, we were interested in examining whether membrane deformability can be altered by ligand binding to transmembrane proteins and, if so, whether this change $(a)$ is affected only by ligands specific for glycophorin $A$ and $(b)$ results from a ligand-induced interaction between glycophorin A and skeletal proteins.

\section{Methods}

Reagents. WGA was purchased from Vector Laboratories, Inc., Burlingame, CA; Maclura pomifera, concanavalin A (Con A), and polyvinylpyrrolidone (PVP) from Sigma Chemical Co., St. Louis, MO; anti$A$ and anti-B antisera from Gamma Biologicals, Houston, TX; Protein

1. Abbreviations used in this paper: Con A, concanavalin A; DI, deformability index; 2,3-DPG, 2,3-diphosphoglycerate; Fab, fragment antibody binding; HRP, horseradish peroxidase; PAS, periodic acidSchiff; PVP, polyvinylpyrrolidone; RT, room temperature; WGA, wheat germ agglutinin. 
A-Sepharose CL-4B from Pharmacia, Inc., Piscataway, NJ; dextran from Pharmacia Fine Chemicals, Uppsala, Sweden; Bio-Rad Immunoblot Assay Kit from Bio-Rad Laboratories, Richmond, CA; Stractan from St. Regis Paper Co., Tacoma, WA. Monoclonal antibody (IgG) with specificity for a determinant on the exoplasmic portion of glycophorin A and no reactivity with glycophorins B or C $(17,18)$ was produced in collaboration with Dr. Tim Heath, Cancer Research Institute, University of California, San Francisco, from hybridoma cells obtained from Dr. Paul Edwards, Ludwig Institute for Cancer Research, Haddow Laboratories, Royal Marsden Hospital, Surrey, England. The antibody was purified by passage over a Protein ASepharose column in 0.1 M sodium phosphate buffer ( $\mathrm{pH} 8.0$ ). Monovalent fragment antibody binding (Fab) was prepared as previously described (19) and its monovalency checked by electrophoresis of unreduced protein in the discontinuous system of Laemmli (20) as described below.

Deformability measurements of intact erythrocytes and resealed membranes. Blood from normal volunteers and from individuals with erythrocyte skeletal protein deficiencies was drawn into heparinized tubes, and the erythrocytes were collected and washed three times in $5 \mathrm{mM}$ Tris, $140 \mathrm{mM} \mathrm{NaCl}$ (pH 7.4). The cells were then resuspended to $0.5 \%$ hematocrit in $3 \mathrm{ml}$ of either dextran $(40,000 \mathrm{~mol} \mathrm{wt}, 25$ $\mathrm{g} / 100 \mathrm{ml}$ in $10 \mathrm{mM}$ phosphate buffer, pH 7.4) or PVP $(4 \mathrm{~g} / 100 \mathrm{ml}$ in $10 \mathrm{mM}$ phosphate buffer, $\mathrm{pH}$ 7.4) and examined by ektacytometry, a laser diffraction method previously described (21). In brief, suspended cells are exposed to an increasing shear stress (0-400 dynes $\left./ \mathrm{cm}^{2}\right)$ and the change in their laser diffraction pattern from sphere to ellipse is measured. This photometric measurement produces a signal, designated deformability index (DI), which quantitates cell ellipticity. By an automatic image analysis system, the DI is recorded as a continuous function of applied shear stress. The DI curve thus produced is a measure of the ability of the cells to deform. During the course of this study, two instruments with different image analysis systems were used. Due to differences in the location at which the optical density is measured, the DI versus the shear stress curves generated by the two instruments are different. In one system, the maximum obtainable DI for normal cells is $\mathbf{0 . 8 5}$ whereas in the other, it is only $\mathbf{0 . 6 0}$. However, the relative increase in rigidity of samples in the two systems is comparable, thus allowing us to compare the results of all the experiments.

Resealed membranes were prepared for ektacytometry by lysing

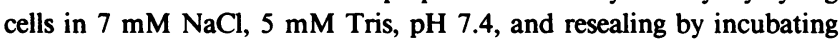
in $140 \mathrm{mM} \mathrm{NaCl}, 5 \mathrm{mM}$ Tris, $\mathrm{pH} 7.4$, for $1 \mathrm{~h}$ at $37^{\circ} \mathrm{C}$. If the membranes were to be resealed in the presence of 2,3-diphosphoglycerate (2,3-DPG), then 2,3-DPG $(5-10 \mathrm{mM})$ was included in the resealing buffer and the lysed membranes were incubated in this buffer for 10 min at $4^{\circ} \mathrm{C}$ and then for $1 \mathrm{~h}$ at $37^{\circ} \mathrm{C}$.

To evaluate the effect of lectins and antibody on deformability, erythrocytes or resealed membranes were resuspended to $0.5 \%$ hematocrit in WGA, 0.5-2.5 $\mu \mathrm{g} / \mathrm{ml}$ in PVP; Con A, 0.1-100 $\mu \mathrm{g} / \mathrm{ml}$ in PVP Maclura pomifera, $0.1-100 \mu \mathrm{g} / \mathrm{ml}$ in PVP; anti-A serum, $60-180 \mu \mathrm{l}$ in dextran; anti-B serum, 60-180 $\mu \mathrm{l}$ in dextran; monoclonal antiglycophorin antibody, $3.8-37.6 \mu \mathrm{g} / \mathrm{ml}$ in dextran; or the Fab fragment of the antibody, $13-59 \mu \mathrm{g} / \mathrm{ml}$ in dextran. The suspensions were incubated for $30 \mathrm{~min}$ at room temperature (RT) and then examined in the ektacytometer.

Density separation of cells. To study deformability characteristics of potentially heterogeneous cell populations from patients' samples, blood was separated on Stractan density gradients as previously described (21). With these gradients, we obtained populations of cells with defined densities and, hence, defined cell hemoglobin concentrations. The isolated subpopulations were then collected and washed three times in phosphate-buffered saline, in preparation for ektacytometry.

Triton X-100 extraction of erythrocytes. Erythrocytes were extracted with Triton by using a method described by Sheetz (22). In brief, freshly drawn erythrocytes were washed two times in $140 \mathrm{mM} \mathrm{NaCl}$, $10 \mathrm{mM}$ sodium phosphate ( $\mathrm{pH} 7.4) ; 2.4 \mathrm{ml}$ of packed cells of hematocrit $65 \%$ was then lysed in Triton X-100 (100 mg/10 10 cells) in
$140 \mathrm{mM} \mathrm{KCl}, 20 \mathrm{mM}$ Hepes, $0.5 \mathrm{mM} \mathrm{MgCl}$, $1 \mathrm{mM}$ EGTA, 0.05 $\mathrm{mM} \mathrm{CaCl}, 2 \mathrm{mM}$ reduced glutathione, and $0.03 \mathrm{mM}$ phenylmethylsulfonyl fluoride. This lysate was layered on a linear sucrose-density gradient (10-60\%) and centrifuged for $1 \mathrm{~h}$ at 22,000 rpm in a Beckman L3-50 ultracentrifuge (Beckman Instruments, Inc., Fullerton, CA). The single visible band was collected and resuspended in $140 \mathrm{mM} \mathrm{KCl}, 20$ mM Hepes, $1 \mathrm{mM}$ EDTA, $2 \mathrm{mM}$ reduced glutathione, and $0.03 \mathrm{mM}$ phenylmethylsulfonyl fluoride (pH 7.4) and centrifuged at $22,000 \mathrm{rpm}$ for $30 \mathrm{~min}$. The pellet was solubilized and analyzed by electrophoresis as described below.

To evaluate Triton extractability after preincubation of erythrocytes with specific ligands, $2.4 \mathrm{ml}$ of packed cells of hematocrit $65 \%$ was resuspended to a total volume of $20 \mathrm{ml}$ in $140 \mathrm{mM} \mathrm{NaCl}, 10 \mathrm{mM}$ sodium phosphate, $\mathrm{pH} 7.4$, containing WGA, $9-90 \mu \mathrm{g} / \mathrm{ml}$, or antiglycophorin antibody, $50-100 \mu \mathrm{g} / \mathrm{ml}$; or agglutinating concentrations of Con A, anti-A serum, or anti-B serum. The cells were incubated 30 $\mathrm{min}$ at $\mathrm{RT}$, then pelleted by centrifugation at $2,000 \mathrm{rpm}$ for $5 \mathrm{~min}$ in a Sorvall RC-2B (DuPont Instruments, Sorvall Biomedical Div., Newtown, CT). These pretreated cells were then processed with Triton as described above.

We performed two types of experiments to rule out the possibilities that the glycophorin extracted from the membranes by Triton might form a complex with WGA and that this complex coincidentally might sediment to the same position on the density gradient as the Tritoninsoluble residues. In the first set of experiments, various concentrations of purified glycophorin A, 70-170 $\mu \mathrm{g} / \mathrm{ml}$, were mixed with WGA, 55 $\mu \mathrm{g} / \mathrm{ml}$, in the Triton lysis buffer. This lysate was then layered on a linear sucrose-density gradient (10-60\%) and centrifuged for $1 \mathrm{~h}$ at 22,000 $\mathrm{rpm}$ in a Beckman L3-50 ultracentrifuge. The single visible band was collected and prepared for analysis by electrophoresis in the manner described above. In the second set of experiments, WGA, 55 $\mu \mathrm{g} / \mathrm{ml}$, was added to Triton lysis buffer containing $2.4 \mathrm{ml}$ of packed cells (hematocrit $65 \%$ ), and these samples were applied to the gradients and processed as above.

Sodium dodecyl sulfate-polyacrylamide gel electrophoresis. Samples for electrophoresis were solubilized in $0.5 \mathrm{M}$ Tris- $\mathrm{Cl}, \mathrm{pH} 6.8,1.25 \%$ sodium dodecyl sulfate (SDS), $0.38 \mathrm{M}$ dithiothreitol, heated to $100^{\circ} \mathrm{C}$ for $3 \mathrm{~min}$, and analyzed in the discontinuous system described by Laemmli (20) on slab gels composed of a separating gel of $10 \%$ acrylamide and a stacking gel of 3\% acrylamide. After electrophoresis, the gels were fixed and stained for protein with Coomassie blue or for carbohydrate with periodic acid-Schiff (PAS) reagent (23).

Immunoblot of Triton-insoluble residues. Antigens were electrophoretically transferred from polyacrylamide SDS gels to nitrocellulose membrane as previously described (24). Unbound reactive sites were blocked by incubation in $3 \%$ gelatin in $20 \mathrm{mM}$ Tris, $500 \mathrm{mM} \mathrm{NaCl}$, pH 7.5 , for $30 \mathrm{~min}$ at RT. The membrane was then incubated in mouse antiglycophorin A IgG in $1 \%$ gelatin, $20 \mathrm{mM}$ Tris, $500 \mathrm{mM}$ $\mathrm{NaCl}$, pH 7.5, for $1 \mathrm{~h}$ at $\mathrm{RT}$, washed twice in $20 \mathrm{mM}$ Tris, $500 \mathrm{mM}$ $\mathrm{NaCl}, 0.05 \%$ Tween-20, $\mathrm{pH} 7.5$, and then incubated in rabbit antimouse IgG conjugated to horseradish peroxidase (HRP) in $1 \%$ gelatin, $20 \mathrm{mM}$ Tris, $500 \mathrm{mM} \mathrm{NaCl}, \mathrm{pH} 7.5$, for $1 \mathrm{~h}$ at RT. Finally, the membrane was washed as above and incubated with HRP color development reagent (containing 4-chloro-1-naphthol).

\section{Results}

Effect of lectins and antiglycophorin antibody on deformability of normal cells. Incubation of red blood cells with WGA in increasing concentrations from 0.5 to $2.5 \mu \mathrm{g} / \mathrm{ml}$, resulted in a dose-dependent decrease in cellular deformability as measured by ektacytometry. The change in DI with increasing concentrations of WGA is shown in Fig. 1. In this figure, we plot DI as a function of shear stress. The DI is a measure of cell ellipticity and, as can be seen by the top curve, plateaus at $\sim 0.8$ for normal erythrocytes. Treatment of cells with increasing concentrations of WGA caused a dose-dependent decrease in 


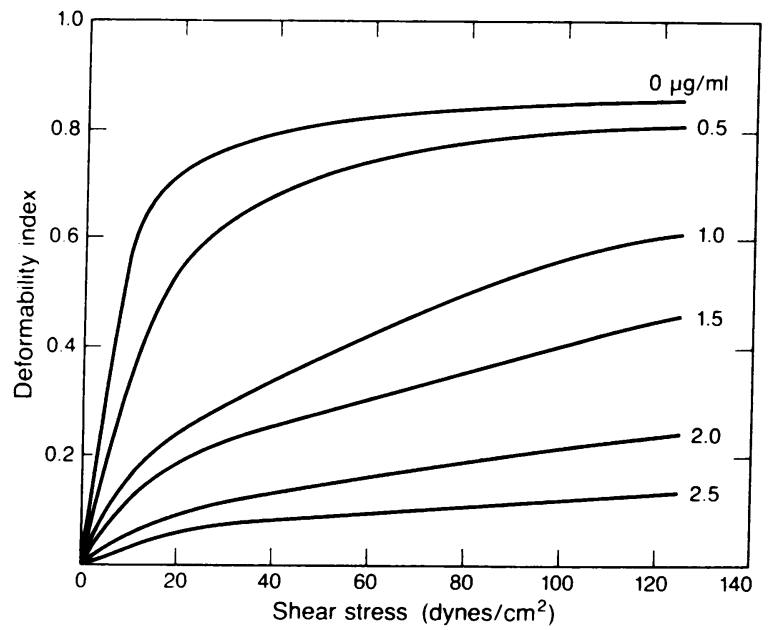

Figure 1. Effect of WGA on erythrocyte deformability. Normal erythrocytes were collected, washed, and resuspended and incubated in PVP containing various concentrations of WGA. The cells were then exposed to increasing shear stress in the ektacytometer and their change from sphere to ellipse was measured. The DI, which quantitates cell ellipticity, is plotted as a continuous function of the applied shear stress. The top curve is of control erythrocytes and the underlying curves are the effect of increasing concentrations of WGA from 0.5 to $2.5 \mu \mathrm{g} / \mathrm{ml}$.

the maximum DI. At $2.5 \mu \mathrm{g} / \mathrm{ml}$ of WGA, the DI was like that of erythrocytes that had been fixed with glutaraldehyde and were totally nondeformable. A similar dose-dependent decrease in deformability was observed in using resealed membranes indicating that the observed decrease in whole cell deformability was due to a change in membrane deformability and not to alterations in surface area-to-volume ratio or to alterations in cytoplasmic viscosity.

To determine whether binding to glycophorin A was required for this change in deformability, we measured deformability after treatment of erythrocytes with lectins that bind to other cell surface receptors and with a monoclonal antibody to glycophorin A. A dose-dependent decrease in erythrocyte deformability was seen after incubation with $0.1-$ $100 \mu \mathrm{g} / \mathrm{ml}$ Maclura pomifera, a lectin that binds to glycophorin A through the carbohydrate residue galactopyranose 2-acetamido-2-deoxygalactopyranose (25). However, the lectin Con A, which binds to the transmembrane protein band 3 (26), did not cause a change in deformability in concentrations from 0.1 to $100 \mu \mathrm{g} / \mathrm{ml}$. The deformability after incubation of erythrocytes with the monoclonal antibody to glycophorin A is shown in Fig. 2. Treatment of cells with increasing concentrations of intact IgG resulted in a dose-dependent decrease in DI.

Because a heavy coat of bound ligand might by itself contribute to altered membrane deformability, we examined the effects of antibodies with specificity for A and B blood group antigens, surface membrane components present in comparable number of copies per cell to glycophorin A (27, 28). Treatment of A-positive cells and B-positive cells with increasing concentrations of their respective antiserum resulted in no change in deformability, the DI curves were all superimposed over the curves of the control, untreated cells. At the concentrations examined, antibody binding was confirmed by

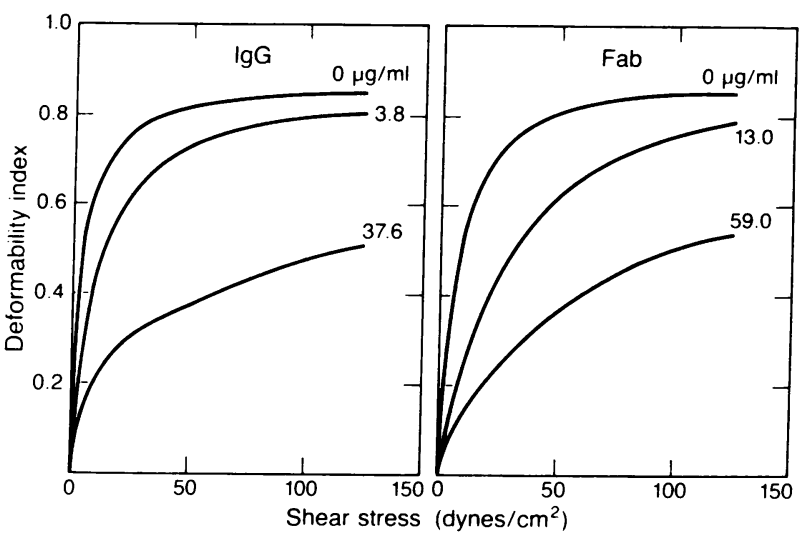

Figure 2. Effect of antiglycophorin A IgG and Fab fragment on erythrocyte deformability. Erythrocytes were collected, washed, and resuspended in dextran containing either antiglycophorin A IgG or its monovalent Fab fragment. The cells were incubated $30 \mathrm{~min}$ at RT and then exposed to increasing shear stress and the DI was measured. In the left panel, the top curve is of control erythrocytes and the underlying curves are the effect of increasing concentrations of IgG. In the right panel, the top curve is of control erythrocytes and the underlying curves are the effect of increasing concentrations of Fab.

the presence of agglutination. In order to measure agglutination, the erythrocytes were pelleted out of the suspending medium used for ektacytometry because agglutination does not occur in the presence of the viscous dextran and the low cell number. After centrifugation, strong agglutination was observed even at the lowest concentrations of anti-A and anti-B used. Increasing the antibody concentration threefold over that concentration resulting in strong agglutination did not change the deformability. It therefore appears that anti-A and anti-B have no effect on membrane deformability.

To evaluate whether the change in membrane deformability could be produced by an agent with monovalent binding properties, a monovalent Fab was prepared from the monoclonal antibody. Before use, this Fab preparation was analyzed on SDS gels. As seen in Fig. 3, the Fab migrated as a band just below the heavy chain of reduced IgG (mol wt 51,000) and the sample did not contain any intact IgG (mol wt 146,000). As shown in Fig. 2, ektacytometry of erythrocytes incubated with Fab $(13-59 \mu \mathrm{g} / \mathrm{ml})$ revealed a dose-dependent decrease in deformability. To determine whether the monoclonal antibody was exerting its effect on deformability only through glycophorin A, we treated En(a-) erythrocytes, which lack glycophorin A (29-32), with the antibody $(30 \mu \mathrm{g} / \mathrm{ml})$ and measured deformability. When the DI of these En(a-) cells was plotted as a function of shear stress, there was no increase in cell rigidity and the DI curve was not significantly different from that of normal cells (Fig. 4). Therefore, the antibody appeared to be modulating deformability specifically through glycophorin A.

When these same En(a-) cells were treated with the lectin WGA, they showed a dose-dependent increase in cell rigidity. This finding suggests that WGA can alter membrane properties not only through its interaction with glycophorin $\mathrm{A}$ but also through additional mechanisms.

Effect of lectins and specific antibody on extractability of glycophorin by Triton X-100. To examine whether binding of a ligand to the exoplasmic portion of glycophorin A might 


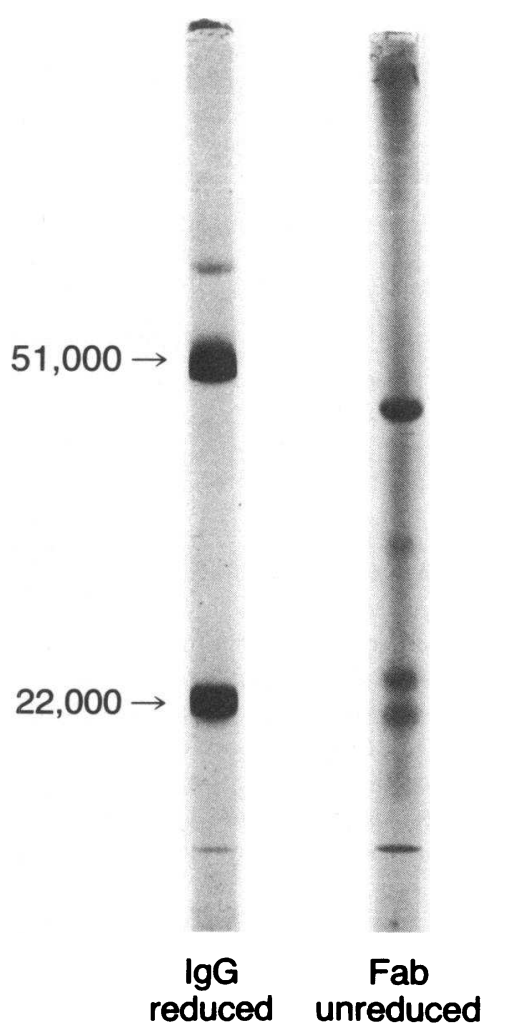

Figure 3. SDS-polyacrylamide gel electrophoresis of monovalent Fab. A sample of Fab was solubilized in the absence of sulfhydralreducing agents and applied to a $10 \%$ polyacrylamide gel. As a source of molecular weight standards, IgG was solubilized in the presence of the sulfhydral-reducing agent dithiothreitol and applied to the gel.

induce an association between the cytoplasmic portion of glycophorin A and membrane skeletal proteins, we prepared Triton-insoluble residues from cells pretreated with WGA or antibody and compared them to residues from untreated cells. On the sucrose gradient the Triton-insoluble residues appeared as a single visible band in the lower third of the gradient.

In initial experiments, we found that when erythrocytes

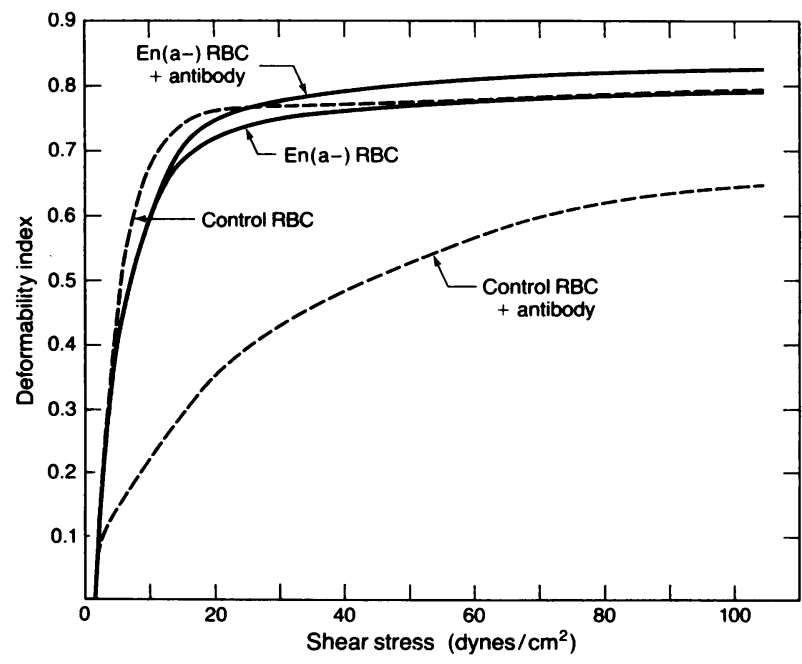

Figure 4. Effect of antiglycophorin A IgG on En(a-) erythrocyte deformability. Erythrocytes were collected, washed, and resuspended in dextran containing antiglycophorin A IgG at $30 \mu \mathrm{g} / \mathrm{ml}$. The cells were incubated $30 \mathrm{~min}$ at $\mathrm{RT}$ and then exposed to increasing shear stress and the DI was measured. The dashed line curves are of control erythrocytes and the solid line curves are of En(a-) erythrocytes.

were treated with increasing concentrations of Triton, increasing amounts of glycophorin A were extracted. We determined that at a concentration of $100 \mathrm{mg}$ of Triton $/ 10^{10}$ cells, glycophorin A was almost completely extracted from the membranes (Fig. 5 , lane 2). Hence, all subsequent experiments were performed at this concentration.

As shown in Fig. 5, SDS-polyacrylamide gels of the Tritoninsoluble residues of cells pretreated with WGA contained a heavy PAS-positive band in the region of the gel where glycophorin A dimer migrates. Gels of the insoluble residues of erythrocytes pretreated with antibody to glycophorin A contained a PAS-positive band with similar migration characteristics (Fig. 5). To confirm that this heavily PAS-positive band was indeed glycophorin A, we prepared an immunoblot of Triton-insoluble residues overlaid with antiglycophorin $\mathrm{A}$ antibody and developed with a secondary anti-mouse IgG coupled to HRP. This preparation (Fig. 6) showed glycophorin $A$ in the dimer and monomer forms in the residues pretreated with ligand, but no glycophorin in the untreated control residues. The total ghost sample contained glycophorin A dimer, glycophorin AB dimer, and glycophorin A monomer.

To examine whether this glycophorin A retention could be caused by lectins or antibodies with specificity for surface membrane components other than glycophorin A, additional experiments were performed with agglutinating concentrations of Con A and with anti-A serum and anti-B serum with blood group antigen A-positive cells and B-positive cells, respectively. Concentrations of Con $\mathrm{A}$ and anti-A and anti-B sera were carefully chosen to produce agglutination so as to be certain that the phenomenon of agglutination itself did not induce retention of glycophorin; no increase in the retention of PASpositive bands with the skeletal proteins was observed.

Lastly, we performed two types of experiments to exclude the possibility that the glycophorin that appeared to be associated with the Triton-insoluble skeletal proteins was actually a complex of extracted glycophorin and ligand, which coincidentally had the same density properties as the inextractable residue. First, when various concentrations of purified glycophorin A (70-170 $\mu \mathrm{g} / \mathrm{ml})$ were mixed with WGA $(55 \mu \mathrm{g} / \mathrm{ml})$,

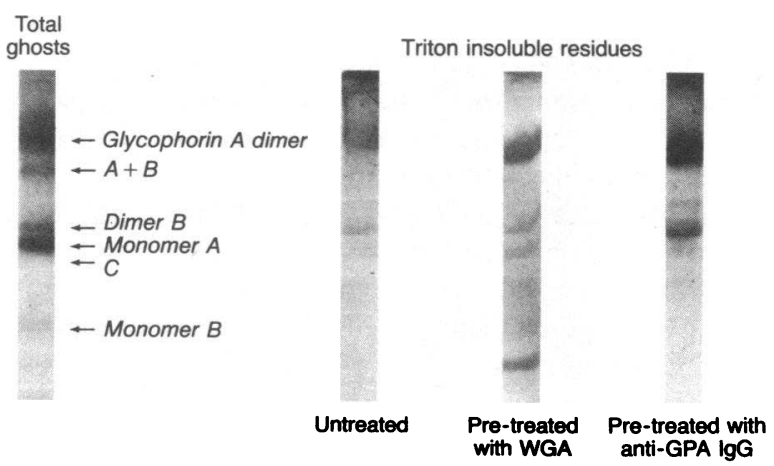

Figure 5. Glycoprotein profiles of Triton X-100-insoluble residues. Erythrocytes were collected, washed, lysed in Triton, layered on a linear sucrose-density gradient, and then centrifuged. The single visible band was collected, washed, and analyzed by electrophoresis. The protein loaded on the SDS-polyacrylamide gels for each sample was derived from an equal number of erythrocytes. On the gels stained with PAS, the three insoluble residues are from the untreated control cells, and from cells pretreated with either WGA or antiglycophorin A (GPA) IgG before Triton extraction. 


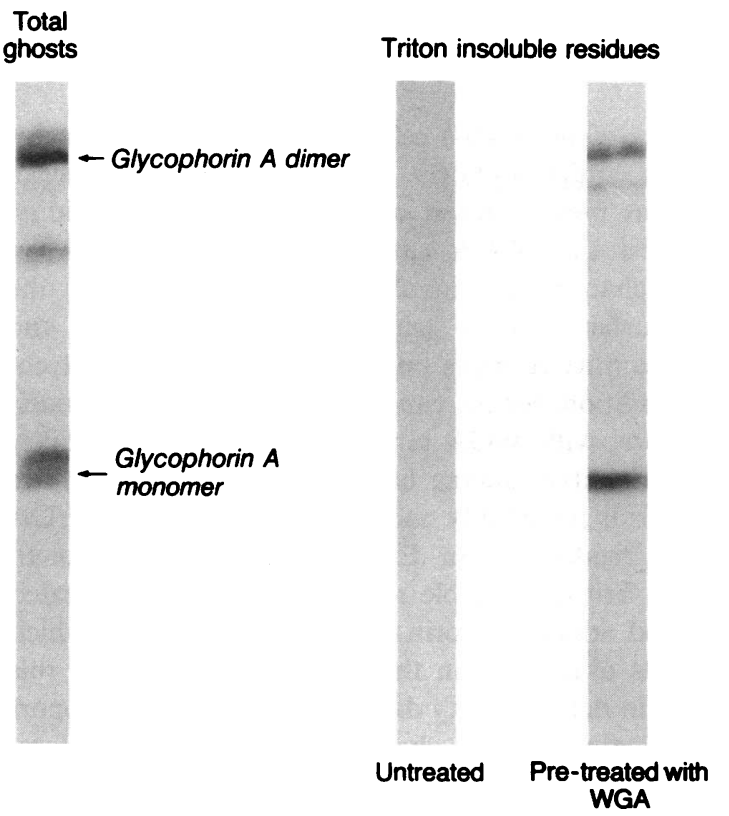

Figure 6. Immunoblot of Triton-insoluble residues. Insoluble residues and total erythrocyte ghosts were electrophoretically transferred from SDS-polyacrylamide gels to nitrocellulose membranes. The membranes were then incubated in mouse antiglycophorin A IgG, followed by an incubation in rabbit anti-mouse IgG conjugated to HRP. Finally, the membranes were incubated in peroxidase color development reagent. The two Triton-insoluble residues on the right are from untreated control cells and from cells pretreated with WGA before Triton extraction.

the complex was localized as a single visible band in the upper third of the $10-60 \%$ sucrose gradient. SDS electrophoretic analysis was performed on both the contents of the visible band and on the region of the gradient corresponding to where the insoluble residue is routinely found. PAS staining revealed glycoprotein in the visible band but no glycoprotein in the insoluble residue region. In that the glycophorin-skeletal protein complex sediments to the bottom third of the gradient, it is clear that the density of the glycophorin-WGA complex was entirely different from that of the insoluble residue of skeletal proteins. In addition, in experiments performed at the different concentrations of purified glycophorin, the locations of the band in the gradient were comparable suggesting no significant concentration dependence for the density of the glycophorinWGA complex. The highest concentration of purified glycophorin used in these experiments was derived by calculating the total amount of glycophorin $A$ that would be available from $2.4 \mathrm{ml}$ of packed cells (hematocrit $65 \%$ ) after complete extraction with Triton.

We employed a second approach to exclude the possibility that the glycophorin that appeared to be associated with the Triton-insoluble skeletal proteins was actually Triton-extracted glycophorin complexed to WGA. We found that, when WGA $(55 \mu \mathrm{g} / \mathrm{ml})$ was added to Triton-extracted nonliganded erythrocytes, the insoluble residues did not contain any glycophorin by PAS staining. This suggests that association of glycophorin with the membrane skeleton requires binding of the ligand before Triton extraction.

Effect of antiglycophorin $A$ antibody on deformability of cells with an abnormal membrane skeleton. If glycophorin A alters membrane deformability through an interaction with skeleton proteins, then, we hypothesized, this effect might be diminished in cells in which the membrane skeleton is disrupted. Polyphosphates are known to dissociate spectrin-actin and spectrin-protein 4.1 interactions $(33,34)$. We, therefore, disrupted skeletal protein associations by resealing membranes in the presence of 2,3-DPG $(5-10 \mathrm{mM})$ and then incubated the resealed membranes with antiglycophorin antibody $(30 \mu \mathrm{g} /$ $\mathrm{ml})$. The changes in DI as a function of shear stress are shown in Fig. 7. In this figure, the shear stress is plotted on a log scale and the DI on a linear scale. To compare the effectiveness of antibody in inducing rigidity, one can, for example, take the DI of 0.4 and see that to achieve that DI control membranes required 17 dynes $/ \mathrm{cm}^{2}$ whereas control membranes treated with antibody required 300 dynes $/ \mathrm{cm}^{2}$. Because the lines are parallel, one can see that membranes treated with antibody required an 18-fold greater shear stress than normal membranes to reach equal deformation at all points along the curve. In similar studies, the membranes resealed in $7.5 \mathrm{mM} 2,3-\mathrm{DPG}$ required 56 dynes $/ \mathrm{cm}^{2}$ to reach a DI of 0.4 whereas those membranes treated with antibody required 520 dynes $/ \mathrm{cm}^{2}$, and were 9.4-fold more rigid. Finally, the membranes resealed in $10 \mathrm{mM}$ 2,3-DPG required 80 dynes/ $\mathrm{cm}^{2}$ to achieve the DI of 0.4 whereas those membranes treated with antibody were 5.1-fold as rigid, requiring 420 dynes $/ \mathrm{cm}^{2}$. Thus, the higher the concentration of 2,3-DPG, the less effective the antibody was in inducing rigidity. It is important to note that the increment of antibody-induced rigidity was different for the membranes of different initial rigidities.

A quantitative reduction in membrane proteins can also disrupt skeletal organization. Hence, we measured the effect of antibody $(30 \mu \mathrm{g} / \mathrm{ml})$ on the deformability of intact erythrocytes from two patients with hemolytic anemias secondary to skeletal protein deficiencies. As shown in Fig. 8, both the protein 4.1-deficient and spectrin-deficient erythrocytes were only about one third as responsive to the monoclonal antibody as normal cells. Because the deformability measurements on

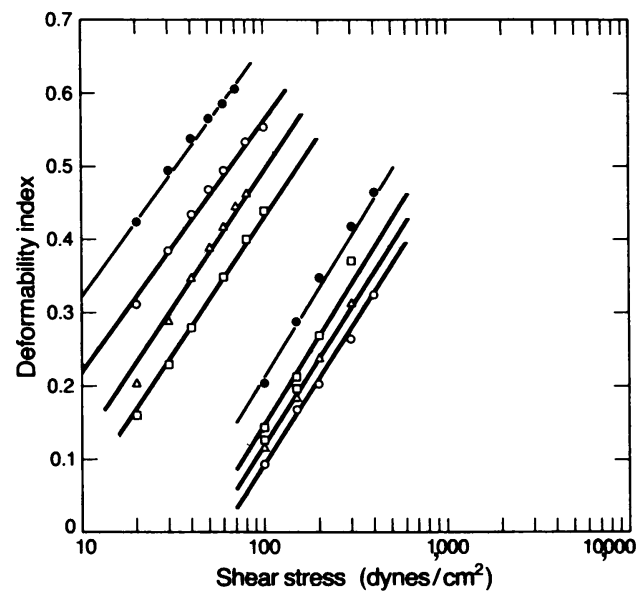

Figure 7. Effect of antiglycophorin A IgG on membranes resealed with 2,3-DPG. Erythrocytes were lysed and then resealed in the presence of 2,3-DPG. The resealed membranes were then incubated in antiglycophorin IgG and examined in the ektacytometer. Note that the DI is plotted on a linear scale and the shear stress is plotted on a log scale. Membranes: control, $\bullet ; 5 \mathrm{mM}, 0 ; 7.5 \mathrm{mM}, \Delta ; 10 \mathrm{mM}$, ․ Membranes plus antibody: control, $\bullet ; 10 \mathrm{mM}, \square ; 7.5 \mathrm{mM}, \Delta ; 5$ $\mathrm{mM}$, o. 


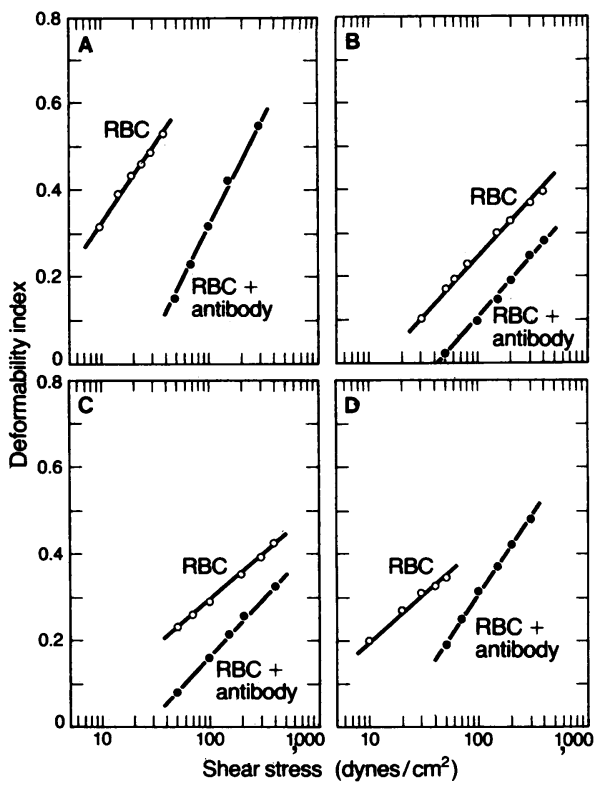

Figure 8. Effect of antiglycophorin A IgG on erythrocytes with skeletal protein deficiencies. Normal erythrocytes and those from patients with protein 4.1 deficiency and spectrin deficiency were collected, washed, resuspended, and incubated in dextran solution containing antiglycophorin A IgG. The cell deformability was then measured by ektacytometry. The DI is plotted on a linear scale and the shear stress on a log scale. The lower right panel shows a subpopulation of cells from the spectrin-deficient individual, which was obtained on a Stractan density gradient. Empty circles are plots of values obtained from erythrocytes only; solid circles are plots of values obtained from erythrocytes with antibody. $(A)$ Normal erythrocytes; $(B)$ protein 4.1-deficient erythrocytes; $(C)$ spectrin-deficient erythrocytes; $(D)$ spectrin-deficient cells, subpopulation.

whole blood samples represent the behavior of a markedly heterogenous population of cells, we also examined the response to antibody of a more defined subpopulation. Blood from the spectrin-deficient individual was separated on a Stractan density gradient and a low-density population was studied. As shown in Fig. 6, the subpopulation of these cells was more deformable than whole blood. Even these more deformable cells were still only one third as responsive to the monoclonal antibody as normal cells.

\section{Discussion}

Our results show that, when erythrocytes were preincubated with the lectin WGA, their deformability was markedly decreased. WGA binds to sialic acid and $\mathrm{N}$-acetylglucosamine residues and one or both of these residues are present on the major erythrocyte transmembrane proteins glycophorin $\mathrm{A}$ and band 3 . To determine whether this change in deformability required ligand binding to a specific transmembrane protein and, if so, to determine which one, we examined the effects of other lectins and of antibodies. With Maclura pomifera, a lectin specific for glycophorin A, a decrease in membrane deformability was observed whereas with Con A, a lectin specific for band 3, deformability remained normal. It seemed likely, therefore, that glycophorin A was the molecule involved in the process resulting in deformability change. Definitive evidence for the requirement for glycophorin came from studies that showed that preincubation of erythrocytes with antiglycophorin antibody resulted in a decreased deformability.
We felt certain that this antibody was exerting its effect through glycophorin A because En(a-) erythrocytes, which lack glycophorin $\mathrm{A}$, had no deformability change in the presence of the antibody.

The studies of the En(a-) cells, which showed that preincubation with antiglycophorin IgG caused no increase in rigidity whereas preincubation with WGA increased rigidity, strongly suggest that WGA can cause rigidity through an additional mechanism not involving glycophorin $\mathrm{A}$. On the erythrocyte surface, WGA can bind to sialic acid and $\mathrm{N}$-acetylglucosamine residues on glycolipids as well as glycoproteins. In addition, lectins can undergo lectin-lectin association. Therefore, with WGA binding, there is the possibility of creating a rigidity-inducing lattice on the external surface of the cell. This is potentially one mechanism by which WGA could induce rigidity in an En(a-) cell. The glycoprotein profiles of the Triton-insoluble residues from cells pretreated with WGA and antiglycophorin IgG are not identical, which further suggests differences in their mode of action. For this reason the lectin deformability data cannot be used to support a mechanism acting through glycophorin $\mathrm{A}$ alone. Therefore, all of our subsequent discussion is based on changes induced by glycophorin-specific antibody.

Two models seemed possible as explanations of the mechanism of antibody-altered deformability. The first of these was that ligand binding creates a rigidity-inducing lattice on the outside surface of the cell either because of cross-links formed by antibody bridging of glycophorin molecules or because of the physical effect of a dense coat of ligand. Our finding that a monovalent Fab fragment induced membrane rigidity argues strongly against protein-protein cross-linking. In addition, high concentrations of anti-A and anti-B antisera did not cause any increased rigidity, which implies that a dense coat of ligand, by itself, does not affect deformability. Because we did not directly quantitate the amount of antibody bound per cell, we cannot completely exclude the possibility that there was less anti-A and anti-B bound than the amount of bound antiglycophorin IgG that caused membrane rigidity. However, we used strongly agglutinating concentrations of anti-A and anti$B$ as the lowest concentrations to be assayed in the ektacytometer and observed no increase in membrane rigidity even at threefold higher concentrations. In light of these results, the model of a rigidity-inducing lattice seems highly unlikely.

Because skeletal proteins determine membrane mechanical properties, our second model was that binding of a ligand to the exoplasmic portion of glycophorin A might induce association between the cytoplasmic portion of glycophorin $A$ and membrane skeletal proteins. If this transmembrane event occurred, one might expect to co-extract glycophorin A with skeletal proteins after ligand binding. Indeed, Triton extracts of cells preincubated with either specific antibody or WGA did contain glycophorin $A$. We felt that the presence of glycophorin A was not a nonspecific effect of cell agglutination that prevented Triton penetration in that the antibody to glycophorin A did not cause agglutination, and the Tritoninsoluble residues from cells preincubated with agglutinating concentrations of Con A, anti-A serum, and anti-B serum did not contain glycophorin A. Our experiments that showed that the purified glycophorin A and WGA complex had a much lower density than the insoluble residues allowed us to rule out the possibility that Triton-extracted glycophorin complexed to WGA coincidentally migrated with the membrane residues. Finally, we felt that protein cross-linking secondary to trans- 
glutaminase activation could not be responsible for our results, in that the experiments were done in the presence of a calcium chelator.

Further support for the model of a ligand-induced association between glycophorin $\mathrm{A}$ and skeletal proteins came from the deformability measurements of erythrocytes with skeletal protein deficiencies and membranes resealed in 2,3-DPG. The dramatically decreased effectiveness of the monoclonal antibody in producing membrane rigidity in such cells suggests that a normal skeleton with a quantitatively normal protein content and normal protein-protein associations is necessary for the glycophorin A deformability effect to occur. Experiments with the spectrin-deficient cells and with the 2,3-DPG-treated membranes showed that the increment in rigidity produced by the antibody was not always the same. In addition, the maximal rigidity of the membranes after treatment with the antibody was different in each case. This set of observations supports the hypothesis that the antibody is exerting a transmembrane effect through skeletal proteins that is dependent upon the state of skeletal proteins. If the antibody were acting independent of the skeletal proteins, we would expect its effect to be the same regardless of the state of the membrane skeleton.

In interpreting the results with abnormal membranes, there is a concern that the decreased responsiveness of these cells to the antibody might be a result of the fact that they are more rigid initially than normal cells. Although we cannot totally rule out this possibility, our findings on spectrin-deficient erythrocytes do not support an important role for the initial rigidity. We found that the starting rigidity of the spectrindeficient erythrocytes was significantly greater than the starting rigidity of the subpopulation of the same cells isolated by density gradient. If initial rigidity was an important factor in the response to the ligand, we would have expected the subpopulation of erythrocytes to be more susceptible to antibody-induced rigidity. However, our finding that the relative increase in rigidity after antibody binding was identical in the two populations and significantly less than the response of normal cells implies that starting rigidity, by itself, cannot explain our findings. The paradox of having membrane rigidity in a membrane treated with a destabilizing agent such as 2,3DPG is something we cannot explain at this time. We have measured membrane deformability and stability of membranes treated with biochemical agents known to perturb skeletal protein associations and found that membrane stability and rigidity are independently modified (unpublished results). For example, diamide treatment increases both stability and rigidity, whereas $N$-ethylmaleimide and 2,3-DPG decrease stability and increase rigidity. These findings imply that the two membrane properties are differently regulated by skeletal protein interactions. Until the effect of 2,3-DPG is clearly defined on a molecular level, we cannot say why this polyphosphate makes the membrane both rigid and unstable.

Other investigators have done studies on the erythrocyte that also suggest an interaction between glycophorin $A$ and skeletal proteins. Feix et al. (35) examined the effects of WGA and phytohemagglutinin binding on spin labels incorporated into sialic acid and membrane protein, and reported that WGA and phytohemagglutinin had pronounced and distinct effects on the protein-specific spin label. In addition, a number of experiments have suggested that spectrin has a role in regulating the mobility of membrane glycoproteins or intramembranous particles. These particles, seen by freeze-cleavage and composed of band 3 and glycophorin $(36,37)$ are normally present in a dispersed state. This dispersion is felt to be maintained at least in part by spectrin. Nicolson and Painter (38), by using colloidal iron hydroxide-labeling electron microscopic techniques, reported that antispectrin antibody can cause aggregation of surface anionic sites. By using freezeetching, Elgsaetter and Branton (39) showed particle aggregation could be induced in ghosts after spectrin depletion. Finally, Sekiguchi and Asano (40) showed that intramembranous particles were aggregated after incubation of cells with Sendai virus (which has as its receptor glycophorin A), but that this aggregation was inhibited by antispectrin antibody.

To date, there are several studies that suggest how glycophorin A may associate with the skeletal proteins. Nigg et al. (41) performed protein rotational diffusion measurements, which suggest a noncovalent association of the intramembranous portion of glycophorin A with that of band 3. Because band 3 is known to bind to protein 2.1 , which in turn is bound to spectrin, it is possible that it is through this band 3 association that glycophorin A affects the skeleton. More recently, Anderson and Lovrien (42) have shown that the cytoplasmic domain of glycophorin can bind to band 4.1. In addition, Anderson and Marchesi (43) have presented evidence in abstract form that this association may be modulated by the state of phosphorylation of phosphoinositides. It must also be considered, however, that our observed results are produced not by a specific protein-protein association, but rather by some nonspecific phenomenon such as trapping of the cytoplasmic portion of glycophorin A in the skeletal network. In addition, a role for membrane lipids can not yet be excluded.

A ligand-induced interaction between transmembrane glycoproteins and cytoskeleton has been shown recently in platelets and neutrophilic leukocytes. Painter and Ginsberg (44), working with the intact platelet, showed that Con A can induce an association between the cytoskeleton and certain surface glycoproteins. Sheterline and Hopkins (45) showed a similar Con A-induced linkage in the neutrophilic leukocyte.

The erythrocyte studies we present here strongly suggest that when certain ligands are bound to the exoplasmic portion of glycophorin A, the cytoplasmic portion of the molecule associates with skeletal proteins, and this association causes a change in membrane deformability.

\section{Acknowledgments}

The authors are grateful to Dr. Heinz Furthmayr for supplying purified glycophorin A; Dr. William Mentzer and Drs. Win Wang, Tom Mueller, and Gerald Presbury for supplying the spectrin-deficient and protein 4.1-deficient erythrocytes, respectively; Phyllis Walker for supplying the En(a-) erythrocytes; Dr. Michael Sheetz for helpful discussions; and Mr. James Harris for assistance with manuscript preparation.

This work was supported in part by grants AM-16095, AM-32094, and AM-26263 from the National Institutes of Health.

\section{References}

1. Marchesi, V. T., T. W. Tillack, R. L. Jackson, J. P. Segrest, and R. E. Scott. 1972. Chemical characterization and surface orientation of the major glycoprotein of the human erythrocyte membrane. Proc. Natl. Acad. Sci. USA. 69:1445-1449.

2. Furthmayr, H. 1977. Structural analysis of a membrane glycoprotein: glycophorin A. J. Supramol. Struc. 7:121-134.

3. Tomita, M., H. Furthmayr, and V. T. Marchesi. 1978. Primary structure of human erythrocyte glycophorin A. Isolation and characterization of peptides and complete amino acid sequence. Biochemistry. 17:4756-4770. 
4. Ross, A. H., R. Radhakrishnan, R. J. Robson, and H. G. Khorana. 1982. The transmembrane domain of glycophorin $A$ as studied by cross-linking using photoactivatable phospholipids. J. Biol. Chem. 257:4152-4161.

5. Rees, D. A., C. W. Lloyd, and D. Thom. 1977. Control of grip and stick in cell adhesion through lateral relationships of membrane glycoproteins. Nature (Lond.). 267:124-128.

6. de Petris, S., and M. C. Raff. 1972. Distribution of immunoglobulin on the surface of mouse lymphoid cells as determined by immunoferritin electron microscopy. Antibody-induced temperaturedependent redistribution and its implications for membrane structure. Eur. J. Immunol. 2:523-535.

7. Cohen, C. M. 1983. The molecular organization of the red cell membrane skeleton. Semin. Hematol. 20:141-158.

8. Marchesi, V. T. 1983. The red cell membrane skeleton: recent progress. Blood. 61:1-11.

9. Evans, E. A., and R. M. Hochmuth. 1977. A solid-liquid composite model of the red cell membrane. J. Membr. Biol. 30:351362.

10. Evans, E. A., and R. Skalak. 1979. Mechanics and thermodynamics of biomembranes: Parts 1 and 2. CRC Crit. Rev. Bioeng. 3: $181-418$.

11. Mohandas, N., J. A. Chasis, and S. B. Shohet. 1983. The influence of membrane skeleton on red cell deformability, membrane material properties and shape. Semin. Hematol. 20:225-242.

12. Haest, C. W. M., T. M. Fischer, G. Plasa, and B. Deuticke 1980. Stabilization of erythrocyte shape by a chemical increase in membrane shear stiffness. Blood Cells. 6:539-553.

13. Lovrien, R. E., and R. A. Anderson. 1980. Stoichiometry of wheat germ agglutinin as a morphology controlling agent and as a morphology protective agent for the human erythrocyte. J. Cell Biol. 85:534-548.

14. Anderson, R. A., and R. E. Lovrien. 1981. Erythrocyte membrane sidedness in lectin control of the $\mathrm{Ca}^{2+}-\mathrm{A} 23187$-mediated discocyte $\rightleftarrows$ echinocyte conversion. Nature (Lond.). 292:158-161.

15. Bhavanandan, V. P., and A. W. Katlie. 1979. The interaction of wheat germ agglutinin with sialoglycoproteins. J. Biol. Chem. 254: 4000-4008.

16. Smith, L., and R. M. Hochmuth. 1982. Effect of wheat germ agglutinin on the viscoelastic properties of erythrocyte membrane. $J$. Cell. Biol. 94:7-11.

17. Edwards, P. A. W. 1980 . Monoclonal antibodies that bind to the human erythrocyte-membrane glycoproteins glycophorin $A$ and band 3. Biochem. Soc. Trans. 8:334.

18. Anstee, D. J., and P. A. W. Edwards. 1982. Monoclonal antibodies to human erythrocytes. Eur. J. Immunol. 12:228-232.

19. Mishell, B. B., and S. M. Shiigi. 1980. Selected methods in cellular immunology. W. H. Freeman and Co., San Francisco. 284286.

20. Laemmli, U. K. 1970. Cleavage of structural proteins during the assembly of the head of bacteriophage T4. Nature (Lond.). 227: 680-685.

21. Mohandas, N., M. R. Clark, M. S. Jacobs, and S. B. Shohet. 1980. Analysis of factors regulating red cell deformability. J. Clin. Invest. 66:563-573.

22. Sheetz, M. P. 1979. Integral membrane protein interaction with Triton cytoskeletons of erythrocytes. Biochim. Biophys. Acta. 557:122-134.

23. Fairbanks, G., T. L. Steck, and D. F. H. Wallach. 1971. Electrophoretic analysis of the major polypeptides of the human erythrocyte membrane. Biochemistry. 10:2606-2617.

24. Burnette, W. N. 1981. 'Western blotting': electrophoretic transfer of proteins from sodium dodecyl sulfate-polyacrylamide gels to unmodified nitrocellulose and radiographic detection with antibody and radioiodinated protein A. Anal. Biochem. 112:195-203.

25. Sarkar, M., A. M. Wu, and E. A. Kabat. 1981. Immunochemical studies on the carbohydrate specificity of Maclura pomifera lectin. Arch. Biochem. Biophys. 209:204-218.
26. Findlay, J. B. C. 1974. The receptor proteins for concanavalin $A$ and Lens culinaris Phytohemagglutinin in the membrane of the human erythrocyte. J. Biol. Chem. 249:4398-4403.

27. Greenburg, C. L., D. H. Moore, and L. A. C. Nunn. 1963 Reaction of $7 \mathrm{~S}$ and $19 \mathrm{~S}$ components of immune rabbit antisera with human group A and AB red cells. Immunology. 6:421-433.

28. Economidou, J., N. C. Hughes-Jones, and B. Gardner. 1967. Quantitative measurements concerning A and B antigen sites. Vox Sang. 12:321-328.

29. Dahr, W., G. Uhlenbruck, J. Leikola, W. Wagstaff, and K. Landfried. 1976. Studies on the membrane glycoprotein defect of En(a-) erythrocytes. I. Biochemical aspects. J. Immunogenet. (Oxf.). 3: 329-346.

30. Gahmberg, C. G., G. Myllyla, J. Leikola, A. Pirkola, and S. Nordling. 1976. Absence of the major sialoglycoprotein in the membrane of human En(a-) erythrocytes and increased glycosylation of band 3 . J. Biol. Chem. 251:6108-6116.

31. Tanner, M. J. A., and D. J. Anstee. 1976. The membrane change in En(a-) human erythrocytes, absence of the major erythrocyte sialoglycoprotein. Biochem. J. 153:271-277.

32. Furthmayr, H. 1978. Structural comparison of glycophorins and immunochemical analysis of genetic variants. Nature (Lond.). 271: 519-524.

33. Sheetz, M. P., and J. Casaly. 1980. 2,3-Diphosphoglycerate and ATP dissociate erythrocyte membrane skeletons. J. Biol. Chem. 255 9955-9960.

34. Wolfe, L. C., S. E. Lux, and V. Ohanian. 1980. Regulation of spectrin-actin binding by protein 4.1 and polyphosphates. J. Cell Biol. 87:203a. (Abstr.)

35. Feix, J. B., L. L. Green, and D. A. Butterfield. 1982. Effects of phytohaemagglutinin, wheat-germ agglutinin, and concanavalin-A on the physical state of sialic acid and membrane proteins in human erythrocyte ghosts: A spin label study. Life Sci. 31:1001-1009.

36. Tillack, T. W., R. E. Scott, and V. T. Marchesi. 1972. The structure of erythrocyte membranes studied by freeze-etching. II. Localization of receptors for phytohemagglutinin and influenza virus to the intramembranous particles. J. Exp. Med. 135:1209-1227.

37. Pinto da Silva, P., and G. L. Nicolson. 1974. Freeze-etch localization of concanavalin A receptors to the membrane intercalated particles of human erythrocyte ghost membranes. Biochim. Biophys. Acta. 363:311-319.

38. Nicolson, G. L., and R. G. Painter. 1973. Anionic sites of human erythrocyte membranes. II. Antispectrin-induced transmembrane aggregation of the binding sites for positively charged colloidal particles. J. Cell. Biol. 59:395-406.

39. Elgsaeter, A., and D. Branton. 1974. Intramembrane particle aggregation in erythrocyte ghosts. I. The effects of protein removal. $J$. Cell Biol. 63:1018-1030.

40. Sekiguchi, K., and A. Asano. 1978. Participation of spectrin in Sendai virus-induced fusion of human erythrocyte ghosts. Proc. Natl. Acad. Sci. USA. 75:1740-1744.

41. Nigg, E. A., C. Bron, M. Girardet, and R. J. Cherry. 1980. Band 3-glycophorin A association in erythrocyte membranes demonstrated by combining protein diffusion measurements with antibodyinduced cross-linking. Biochemistry. 19:1887-1893.

42. Anderson, R. A., and R. E. Lovrien. 1984. Glycophorin is linked by band 4.1 protein to the human erythrocyte membrane skeleton. Nature (Lond.). 307:655-658.

43. Anderson, R. A., and V. T. Marchesi. 1983. Polyphosphoinositide modulation of glycophorin-protein 4.1 interactions: a possible mechanism for regulation of the red cell membrane skeleton. J. Cell Biol. 97:297a. (Abstr.)

44. Painter, R. G., and M. Ginsberg. 1982. Concanavalin A induces interactions between surface glycoproteins and the platelet cytoskeleton J. Cell. Biol. 92:565-573.

45. Sheterline, P., and C. R. Hopkins. 1981. Transmembrane linkage between surface glycoproteins and components of the cytoplasm in neutrophil leukocytes. $J$. Cell. Biol. 90:743-754. 